\title{
A Novel Negative Fe-Deficiency-Responsive Element and a TGGCA-Type-Like FeRE Control the Expression of FTR1 in Chlamydomonas reinhardtii
}

\author{
Xiaowen Fei, ${ }^{1,2}$ Mats Eriksson, ${ }^{3}$ Yajun Li, ${ }^{1}$ and Xiaodong Deng ${ }^{1}$ \\ ${ }^{1}$ Key Laboratory of Tropical Crop Biotechnology, Ministry of Agriculture, Institute of Tropical Bioscience and Biotechnology, \\ Chinese Academy of Tropical Agricultural Science, Haikou 571101, China \\ ${ }^{2}$ Department of Biochemistry, Hainan Medical College, Haikou 571101, China \\ ${ }^{3}$ Umeå Plant Science Center, Umeå University, 90187 Umeå, Sweden
}

Correspondence should be addressed to Xiaodong Deng, xiaodong9deng@hotmail.com

Received 13 October 2009; Accepted 30 December 2009

Academic Editor: Gopi K. Podila

Copyright (c) 2010 Xiaowen Fei et al. This is an open access article distributed under the Creative Commons Attribution License, which permits unrestricted use, distribution, and reproduction in any medium, provided the original work is properly cited.

\begin{abstract}
We have reported three Fe-deficiency-responsive elements (FEREs), FOX1, ATX1, and FEA1, all of which are positive regulatory elements in response to iron deficiency in Chlamydomonas reinhardtii. Here we describe FTR1, another iron regulated gene and mutational analysis of its promoter. Our results reveal that the FeREs of FTR1 distinguish itself from other iron response elements by containing both negative and positive regulatory regions. In FTR1, the $-291 /-236$ region from the transcriptional start site is necessary and sufficient for Fe-deficiency-inducible expression. This region contains two positive FeREs with a TGGCA-like core sequence: the FtrFeRE1 (ATGCAGGCT) at -287/-279 and the FtrFeRE2 (AAGCGATTGCCAGAGCGC) at -253/-236. Furthermore, we identified a novel FERE, FtrFeRE3 (AGTAACTGTTAAGCC) localized at -319/-292, which negatively influences the expression of FTR1.
\end{abstract}

\section{Introduction}

Iron is an essential nutrient for virtually every organism on the earth, because it participates as a cofactor in numerous essential enzymatic reactions involved in electron transfer and many other physiological processes. Symptoms of acquired or inherited iron-deficiency have been reported in many organisms, but iron uptake and the regulation of iron metabolism are best characterized at the molecular level in Saccharomyces cerevisiae $[1,2]$. S. cerevisiae has three known pathways for iron uptake, two for free iron and one for siderophore bound iron. Free iron can be acquired either by a high- or by a low-affinity uptake system. Under iron deficient conditions, the high-affinity system is induced, which consists of an iron reductase (FRE1/FRE2) $[3,4]$ and a transport complex consisting of one of a multicopper oxidase (FET3) and an iron transporter (FTR1) $[5,6]$. Free $\mathrm{Fe}^{3+}$ is reduced by FRE1/FRE2 to $\mathrm{Fe}^{2+}$ and is subsequently reoxidized to $\mathrm{Fe}^{3+}$ by FET3 at the site of FTR1, which transports the iron into the cell. Under iron sufficient conditions, iron uptake is facilitated by the low-affinity iron transporter FET4 [7]. FET4 is an $\mathrm{Fe}^{2+}$ transporter that also transports $\mathrm{Cu}^{+}$and $\mathrm{Zn}^{2+}$ into the cell [8-10]. These three iron uptake systems are regulated by two transcription factors, Aft $1 \mathrm{p}$ and Aft2p [11-14]. These two transcription factors are paralogous (39\% homology); they recognize a common DNA element (T/C) (G/A)CACCC [15]. Aft1p is localized in the cytoplasm under iron-replete conditions, but is relocated to the nucleus if the cell becomes iron deficient and thereby increases the expression of the iron regulation genes [16]. The localization of Aft $2 p$ has not been determined. Although Aft $1 \mathrm{p}$ and Aft2p bind to the same promoter motif, they do not control the same subset of genes [17]. Some genes are regulated by both Aft1p and Aft2p (e.g., frel, ftrl, and fet3), but other genes are only regulated by one of them but not by the other $[18,19]$. 
In higher plants, two major strategies to acquire iron have evolved. Nongraminaceous plants use Strategy I, which is a reduction strategy. The solubility of $\mathrm{Fe}^{3+}$ is increased in the rhizosphere by an $\mathrm{H}^{+}$-ATPase that extrudes protons. Soluble $\mathrm{Fe}^{3+}$ is then reduced to $\mathrm{Fe}^{2+}$ by an iron reductase, and taken up into the cell by an iron transporter. Arabidopsis thaliana is the best-studied Strategy I plant and several genes encoding proteins involved in iron uptake have been sequenced, for example, FRO2 encodes a reductase that catalyze $\mathrm{Fe}^{3+}$ to $\mathrm{Fe}^{2+}$ reduction [20], and IRT1 and IRT2 encode an $\mathrm{Fe}^{2+}$ transporter localized in external cell layers of the root subapical zone, which facilitates the $\mathrm{Fe}^{2+}$ uptake into the roots [21-23]. Strategy II plants (graminaceous monocots) use a chelation strategy. Phytosiderophores are secreted into the rhizosphere where they form stable $\mathrm{Fe}^{3+}$ chelates, and these chelates are transported into the cells by specific transport systems.

Although studies on regulation of iron metabolism in photosynthetic eukaryotes are just getting started, recently more and more reports in this field have been published. Iron related elements of photoferritin gene have been identified as IDRS (iron-dependent regulatory sequence) in maize and Arabidopsis and FRE (iron regulatory sequence) in soybean. The IDRS harbors the conserved sequence CACGAGGCCGCCAC [24]; whereas the FRE contains a symmetric sequence sufficient to derepress the ferritin gene when iron is abundant [25]. In barley, IDS1 and IDS2 induced specifically by iron-deficiency stress are metallothionein-like genes $[26,27]$. There are two irondeficiency-inducible elements in IDS2, IDE1 (ATCAAGCATGCTTCTTGC) at $-153 /-136$ and IDE2 (TTGAACGGCAAGTTTCACGCTGTCACT) at $-262 /-236$ [28]. The tomato FER gene, together with its Arabidopsis ortholog FIT gene, functions as transcriptional factors in the irondeficiency-signaling pathway [29-31]. Both FER and FIT encode a basic helix-loop-helix (bHLH) transcriptional factor that is expressed in roots. Down regulation of the FIT mRNA leads to reduction in the mRNA levels of FRO2 and IRT1, whose expression also needs the binding partner BHLH38 and BHLH39 when iron is limited [32, 33]. Coexpression of FIT with either BHLH38 or BHLH39 in yeast cells activates the expression of GUS controlled by IRT1 and FRO2 promoters, indicating that FIT and BHLH38/39 act directly to induce expression of FRO2 and IRT1 [33].

In Chlamydomonas reinhardtii, the expression of several genes, including FOX1, FTR1, FER1, ATX1, and FEA1 is induced by Fe-deficiency [34-37]. So far, two types of FeREs have been identified in Chlamydomonas. One is the FOX1-type with two regions that contain the core sequence $\mathrm{C}(\mathrm{A} / \mathrm{G}) \mathrm{C}(\mathrm{A} / \mathrm{G}) \mathrm{C}(\mathrm{G} / \mathrm{T})[38$, and the other is the TGGCAType that harbors the sequence TGGCA $[39,40]$. The FTR1 gene codes an iron permease whose mRNA is accumulated 2 to high levels in Fe-deficiency cells [34]. However, th ecisacting elements that govern such response are unknown. In this paper, we report the identification of three FeREs in FTR1 gene, two as positive $\mathrm{Fe}$-deficiency-responsive elements and one as a novel negative FeRE.

\section{Materials and Methods}

2.1. Strains and Culture Conditions. The recipient strain of all transformations, Chlamydomonas reinhardtii strain CC425 (cw15 arg2), was grown in TAP (tris-acetate phosphate) liquid medium supplemented with $250 \mu \mathrm{g} / \mathrm{mL}$ arginine [41], and transformants were grown in either $+\mathrm{Fe}(18 \mu \mathrm{M} \mathrm{Fe})$ or $-\mathrm{Fe}(0 \mu \mathrm{M} \mathrm{Fe})$ TAP medium. Liquid cultures were grown under continuous light of $150 \mu \mathrm{mol} \times \mathrm{m}^{-2} \times \mathrm{s}^{-1}$ at $25^{\circ} \mathrm{C}$ in shaking conditions of $250 \mathrm{rpm}$. Strains on TAP-agar plates were incubated at a light intensity of $100 \mu \mathrm{mol} \times \mathrm{m}^{-2} \times \mathrm{s}^{-1}$ at $22^{\circ} \mathrm{C}$.

2.2. Deletion Constructs of FTR1. Primers used to make the deletion constructs of FTR 1 are list in Table 2.

Target DNA fragments were generated by PCR using the $5^{\prime}$ and $3^{\prime}$ primers, which were then inserted in SalI/KpnI sites of pJD54 or in KpnI site of pJD100 to make the described deletion constructs. To make constructs FtrD5, an overlap extension PCR method was used. First, the DNA fragment between -1179 and -291 of FTR1 was amplified with forward primer $\mathrm{A}$ and reverse primer $\mathrm{B}$. Then the fragment between -253 and +58 was amplified by primer $C$ and D. The PCR products of these two reactions were mixed and used as the template for a third reaction with primers $\mathrm{A}$ and $\mathrm{D}$. This manipulation produced a fragment from position -1179 to +58 of FTR1 but with the $-291 /-254$ removed. The fragment was then cloned into the KpnI and SalI sites of pJD54.

2.3. Constructs Used in Scanning Mutagenesis Assay. Substitution mutations in FTR1 promoter sequence were generated by amplifying the FTR1 promoter region with one primer containing the target mutation and a second primer outside the FeREs region $(-291$ to -236 or -319 to -292$)$ relative to the FTR 1 transcription start. Mutated fragments were cloned into the KpnI site of pJD100. All constructs (as well as every other construct mentioned in this paper) were confirmed by DNA sequencing.

2.4. Transformation. The cells used for transformation ( $C$. reinhardtii strain $\mathrm{CC} 425$ ( $\mathrm{cw} 15$ arg2)) were grown to a cell density of $1-2 \times 10^{6}$ cells $/ \mathrm{mL}$, and constructs were introduced into the cells by the glass bead method [43] through cotransformation with the plasmid pARG7.8 that contains the selectable marker arginosuccinyl lyase [44]. Briefly, cells were collected by centrifugation, washed twice and were resuspended in TAP medium without arginine to a cell density of approximately $1 \times 10^{8}$ cells $/ \mathrm{mL}$. DNA $(2 \mu \mathrm{g}$ of construct and $10 \mu \mathrm{g}$ pARG7.8 each) and cells $(400 \mu \mathrm{L})$ were mixed with polyethylene glycol $(100 \mu \mathrm{L} 20 \%)$ and $300 \mathrm{mg}$ sterile glass beads. After being vortexed for $15 \mathrm{~s}$ on a benchtop mixer, cells were washed from the glass-beads and plated on TAP agar without arginine. After seven days colonies were transferred in duplicate to $+/-$ Fe TAP agar plates without arginine. 
TABLE 1: The comparison of Ars mRNA levels and Ars activities of selective transformants.

\begin{tabular}{lcccccc}
\hline \multirow{2}{*}{ Constructs } & \multicolumn{3}{c}{ Ars mRNA Abundances } & \multicolumn{3}{c}{ Ars Activities $(\mathrm{nmol} p$-nitrophenol $\times$ min } \\
& $-\mathrm{Fe}(0 \mu \mathrm{M})$ & $+\mathrm{Fe}(18 \mu \mathrm{M})$ & $-\mathrm{Fe} / \mathrm{Fe}$ & $-\mathrm{Fe}(0 \mu \mathrm{M})$ & $+\mathrm{Fe}(18 \mu \mathrm{M})$ & $-\mathrm{cells})$ \\
\hline Ftr1179 & 115 & 22 & 5 & 2.97 & 0.58 & 5 \\
Ftr291 & 372 & 36 & 10 & 6.86 & 0.76 & 1 \\
Ftr253 & 2 & 2 & 1 & 0.31 & 0.32 & 1 \\
$319-194$ & 1 & 1 & 1 & 0.29 & 0.26 & 6 \\
$291-194$ & 133 & 26 & 5 & 3.49 & 0.55 & 7 \\
FtrM291F & 186 & 29 & 6 & 5.41 & 0.81 & 1 \\
FtrM287F & 3 & 2 & 2 & 0.33 & 0.29 & \\
\hline
\end{tabular}

Ars mRNA levels were assessed by real-time PCR in $-\mathrm{Fe}(0 \mu \mathrm{M})$ and $+\mathrm{Fe}(18 \mu \mathrm{M})$ conditions. Data were calculated by the $2^{-\Delta \Delta C T}$ method [29]. The Ars activities of the selected transformants were detected as described by Davies et al. [42].

TABLe 2: Primers used in amplification of the fragments for making the deletion constructs.

\begin{tabular}{|c|c|c|c|}
\hline Constructs & 5'Primers & 3'Primers & The position \\
\hline Ftr1179 & 1179F TCGGTACCTTACTGGCTTACTGGCA & 58R GAAGTCGAC CGTCCTGATGAGAAAGG & $-1179 /+58$ \\
\hline Ftr917 & 917F TAAGGTACCGAACCTAACAAATGGCA & 58R GAAGTCGAC CGTCCTGATGAGAAAGG & $-917 /+58$ \\
\hline Ftr718 & 718F TAAGGTACCCCAAGATCACCCGTCTG & 58R GAAGTCGAC CGTCCTGATGAGAAAGG & $-718 /+58$ \\
\hline Ftr511 & 511F CTTGGTACCTTCCAGCCCGACTGAAT & 58R GAAGTCGAC CGTCCTGATGAGAAAGG & $-511 /+58$ \\
\hline Ftr355 & 355F ATTGGTACCCGACACACCTTGCTCCA & 58R GAAGTCGAC CGTCCTGATGAGAAAGG & $-355 /+58$ \\
\hline Ftr291 & 291F GACGGTACCTCACATGCAGGCTCCTCCT & 58R GAAGTCGAC CGTCCTGATGAGAAAGG & $-291 /+58$ \\
\hline Ftr253 & 253F TAAGGTACCAAGCGATTGCCAGAGCG & 58R GAAGTCGAC CGTCCTGATGAGAAAGG & $-253 /+58$ \\
\hline Ftr161 & 161F TAAGGTACCATGCCACCGATTACGAG & 58R GAAGTCGAC CGTCCTGATGAGAAAGG & $-161 /+58$ \\
\hline Ftr59 & 59F TAAGGTACCGGAGCGACGGTAAACGG & 58R GAAGTCGAC CGTCCTGATGAGAAAGG & $-59 /+58$ \\
\hline Ftr24 & 24F ATCGGTACCATATAGCACTCTAAC & 58R GAAGTCGAC CGTCCTGATGAGAAAGG & $-24 /+58$ \\
\hline $355-162$ & 355F GACGGTACCCGACACACCTTGCTCCACCG & 162R GACGGTACCGCATGCGTTCTCTTATTG & $-355 /-162$ \\
\hline $355-194$ & 355F GACGGTACCCGACACACCTTGCTCCACCG & 194R GACGGTACCGACATTATCAGCTAGCG & $-355 /-194$ \\
\hline $334-194$ & 334F GACGGTACCGAGCGAGGCTACTGGTC & 194R GACGGTACCGACATTATCAGCTAGCG & $-334 /-194$ \\
\hline $291-162$ & 291F GACGGTACCTCACATGCAGGCTCCTCCT & 162R GACGGTACCGCATGCGTTCTCTTATTG & $-291 /-162$ \\
\hline $291-194$ & 291F GACGGTACCTCACATGCAGGCTCCTCCT & 194R GACGGTACCGACATTATCAGCTAGCG & $-291 /-194$ \\
\hline $291-215$ & 291F GACGGTACCTCACATGCAGGCTCCTCCT & 215R GACGGTACCCAGTGCATG GCGACAGCC & $-291 /-215$ \\
\hline $291-236$ & 291F GACGGTACCTCACATGCAGGCTCCTCCT & 236R GACGGTACCGCGCTCTG GCAATCGCTTC & $-291 /-236$ \\
\hline $291-254$ & 291F GACGGTACCTCACATGCAGGCTCCTCCT & 254R GACGGTACCCGCGCGTGCCCGGTCGG & $-291 /-254$ \\
\hline FtrD5 (overlap & A,1179F AAGGTACCGAACCTAACAAATGGCA & B,291R GCAATCGCTTGGCTTAACAGTTACTG & $-1179 /+58$ with \\
\hline extension PCR) & C,253F CTGTTAAGCCAAGCGATTGCCAGAG & D,58R GAAGTCGACCGTCCTGATGAGAAAGG & $-291 /-254$ removal \\
\hline
\end{tabular}

2.5. Cotransformation Frequency Detection. To determine the frequency of cotransformation, 16 out of arginine autotrophic transformants were transferred and maintained for 5 days on TAP agar medium. DNA from these transformants was isolated by using the E-Z 96 well plant DNA kit (Omega Bio-tek) and was used as templates for PCR amplification of the FTR1-ARS junction with a forward primer in the FTR1 promoter region and a reverse primer ArsR(5' -TTCTGAATGGCGTCCTGGTC-3'), which is corresponding to amino acid 36 to 42 of the $A R S$ coding sequence.

2.6. Arylsulfatase Activity Assay. Arylsulfatase activity was assayed as described by Davies et al. [42]. Before inoculation, 5-bromo-4-chloro-3-indolyl sulfate (XSO4) (Sigma Chemical Co.) was added to plates with -Fe TAP solid medium at a concentration of $10 \mathrm{mM}$. Transformants expressing arylsulfatase activity were identified by the appearance of a blue halo around the colonies one day after inoculation. For quantitative analysis of arylsulfatase, cells were first collected by centrifugation. $100 \mu \mathrm{L}$ of the culture supernatant was added to $500 \mu \mathrm{L}$ buffer that contains $0.1 \mathrm{M}$ Glycine- $\mathrm{NaOH}$ pH 9.0, $10 \mathrm{mM}$ Imidazole, $4.5 \mathrm{mM}$ p-Nitrophenyl sulfate. The reaction was incubated at $27^{\circ} \mathrm{C}$ for 27 minutes. The reaction was stopped by the addition of $2 \mathrm{~mL}$ of $0.25 \mathrm{M}$ $\mathrm{NaOH}$ and the absorbance at $410 \mathrm{~nm}$ was determined. The standard curve of p-nitrophenol (Sigma Chemical Co) was established in $0.2 \mathrm{M} \mathrm{NaOH}$ [45].

2.7. Real-Time PCR. Transformants for real-time PCR analysis were cultured in $-\mathrm{Fe}(0 \mu \mathrm{M})$ and $+\mathrm{Fe}(18 \mu \mathrm{M})$ TAP liquid medium to a cell density of 2 to $5 \times 10^{6}$ cell $/ \mathrm{mL}$. 


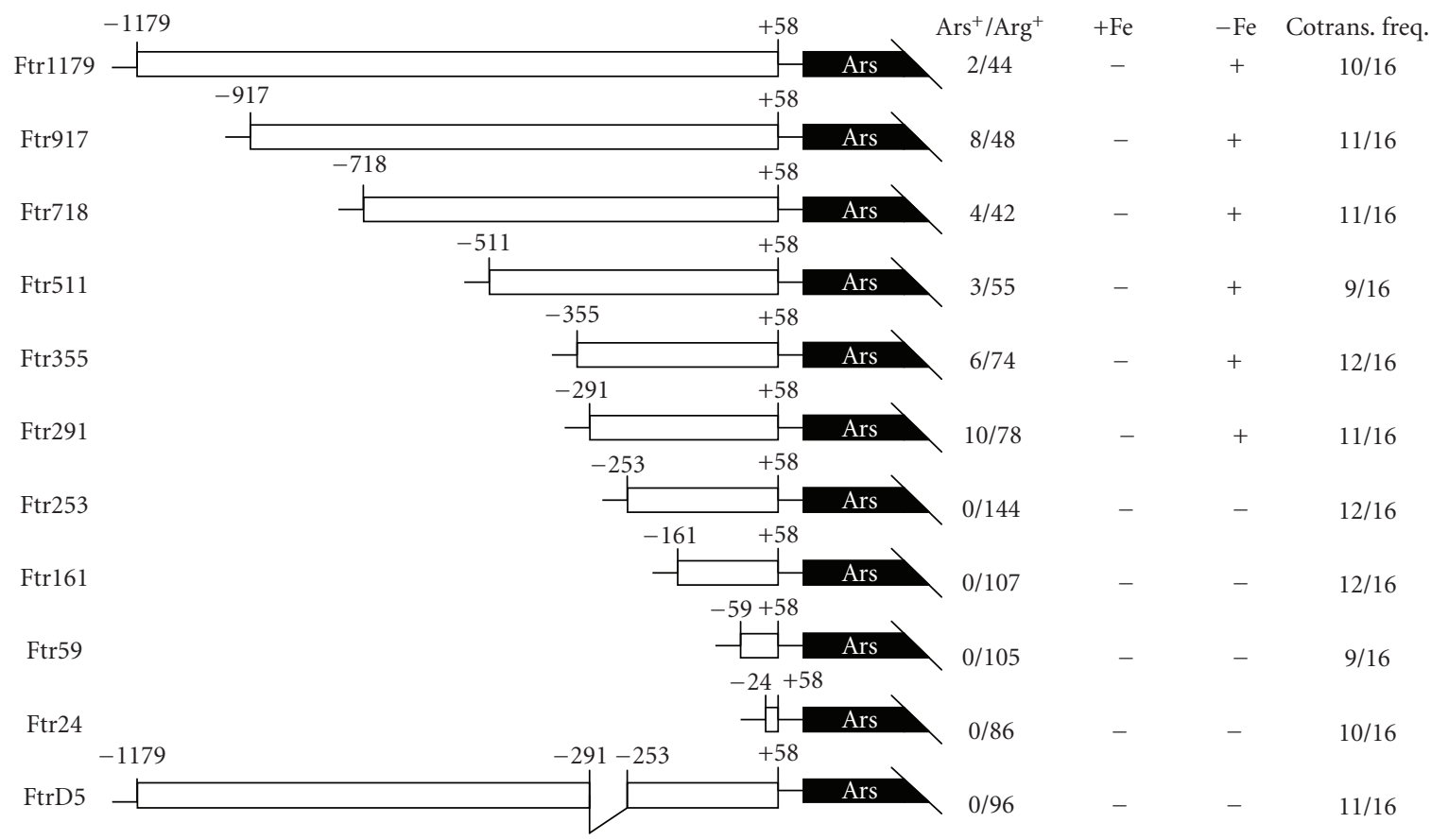

FIgURE 1: $5^{\prime}$ deletion analysis of the FTR1 promoter region. A series of $5^{\prime}$ deletions from -1179 to +58 of FTR 1 promoter region were amplified by PCR and fused to the Ars reporter gene in pJD54, and transformed into the arginine requiring C. reinhardtii strain CC425 along with pArg7.8. Arginine independent colonies were transferred to +/- Fe TAP plates and sprayed with $10 \mathrm{mM} \mathrm{XSO}_{4}$ to visualize arylsulfatase activity. FtrD5 was constructed by fusing the $-1179 /+58$ fragment lacking the $-291 /-254$ region to pJD54. The fraction of arylsulfatase expressing colonies among the arginine independent colonies is expressed as $\mathrm{Ars}^{+} / \mathrm{Arg}^{+} ;+\mathrm{Fe}$ and $-\mathrm{Fe}$ indicate growth on $+/-\mathrm{Fe}$ TAP plates, and $(+)$ and $(-)$ indicate expression of the arylsulfatase gene. The cotransformation frequency was tested by PCR from 16 random selected Arg independent transformants.

RNA was extracted by using the TRIzol Reagent (Shanghai Sangon Biological Engineering Technology \& Service Co.). Single strand cDNA was synthesized by Bio-Rad Iscript selected cDNA synthesis kit using $100 \mathrm{ng}$ RNA and random primers performed at as $65^{\circ} \mathrm{C} 5$ minutes, $25^{\circ} \mathrm{C} 5 \mathrm{~min}$ utes, $42^{\circ} \mathrm{C} 50$ minutes. The real-time PCR was performed on a BioRad iCycler iQ real-timePCR Detection System using SYBR Green as a fluorescent dye. Each reaction was performed in a final volume of $25 \mu \mathrm{L}$ with the following components: 0.2 pmoles of each primer, $1 \mu \mathrm{L}$ of cDNA, $12.5 \mu \mathrm{L}$ of SYBR Green Mix (Invetrogen SYBR Greener QPCR), and water was used to adjust the volume to $25 \mu \mathrm{L}$. The iCycler run protocol was: denaturing at $95^{\circ} \mathrm{C}, 5 \mathrm{~min}$; 40 (denaturing at $95^{\circ} \mathrm{C}, 30$ seconds; annealing at $54^{\circ} \mathrm{C}, 30$ seconds; amplification at $72^{\circ} \mathrm{C}, 15$ seconds). The specificity of the PCR amplification was examined by a melting curve program $\left(55-100^{\circ} \mathrm{C}\right.$ with a heating rate of $\left.0.5^{\circ} \mathrm{C} / \mathrm{s}\right)$. The 18S rRNA was used as controls with the primers, 18SrRNAF (5'-TCAACTTTCGATGGTAGGATAGTG-3') and 18 SrRNAR $\left(5^{\prime}\right.$-CCGTGTCAGGATTGGGTAATTT- $\left.3^{\prime}\right)$. Expression of this gene was measured and shown to be constitutive under all the conditions used in this work. Primers, ARSF1 (5'-ATGGGTGCCCTCGCGGTGTTC-3') and ARSR1 ( $5^{\prime}$-GTAGCGGATGTACTTGTGCAG-3'), were designed specifically for Ars cDNA. The amplification rate of each transcript $(\mathrm{Ct})$ was calculated by the PCR Baseline Subtracted method performed in the iCycler software at a constant fluorescence level. Cts were determined over three repeats. Relative fold differences were calculated based on the relative quantification analytical method $\left(2^{-\Delta \Delta C T}\right)$ using $18 \mathrm{~S}$ rRNA amplification as internal standard [46].

\section{Results}

3.1. The -291/-254 Region Is Essential for Fe-DeficiencyMediated Induction of FTR1 Expression. To study the promoter region of FTR1, using cDNA information of FTR1 (GeneBank accession number AF478411) and sequence information from the JGI Chlamydomonas genomic database (http://genome.jgi-psf.org/), we first cloned a $1237 \mathrm{bp}$ $(-1179$ to +58$)$ upstream fragment of FTR1 into pBluescript II SK(+). The resulting plasmid was used to generate a series of $5^{\prime}$ end nested deletion constructs (Figure 1, Ftr1179 to Ftr24). Deletion constructs from this manipulation were delivered into $C$. reinhardtii CC425 by cotransformation with pArg7.8 [43, 44] and the response of these constructs to different iron concentrations was analyzed.

Our results showed that a region spanning nucleotide -291 to -254 was essential for the induction of FTR1 under Fe-deficiency condition (Figure 1, Ftr1179 to Ftr24). Consistent with this notion, removal of the $-291 /-254$ region abolished the low Fe-mediated induction of the reporter gene (Figure 1, FtrD5). 


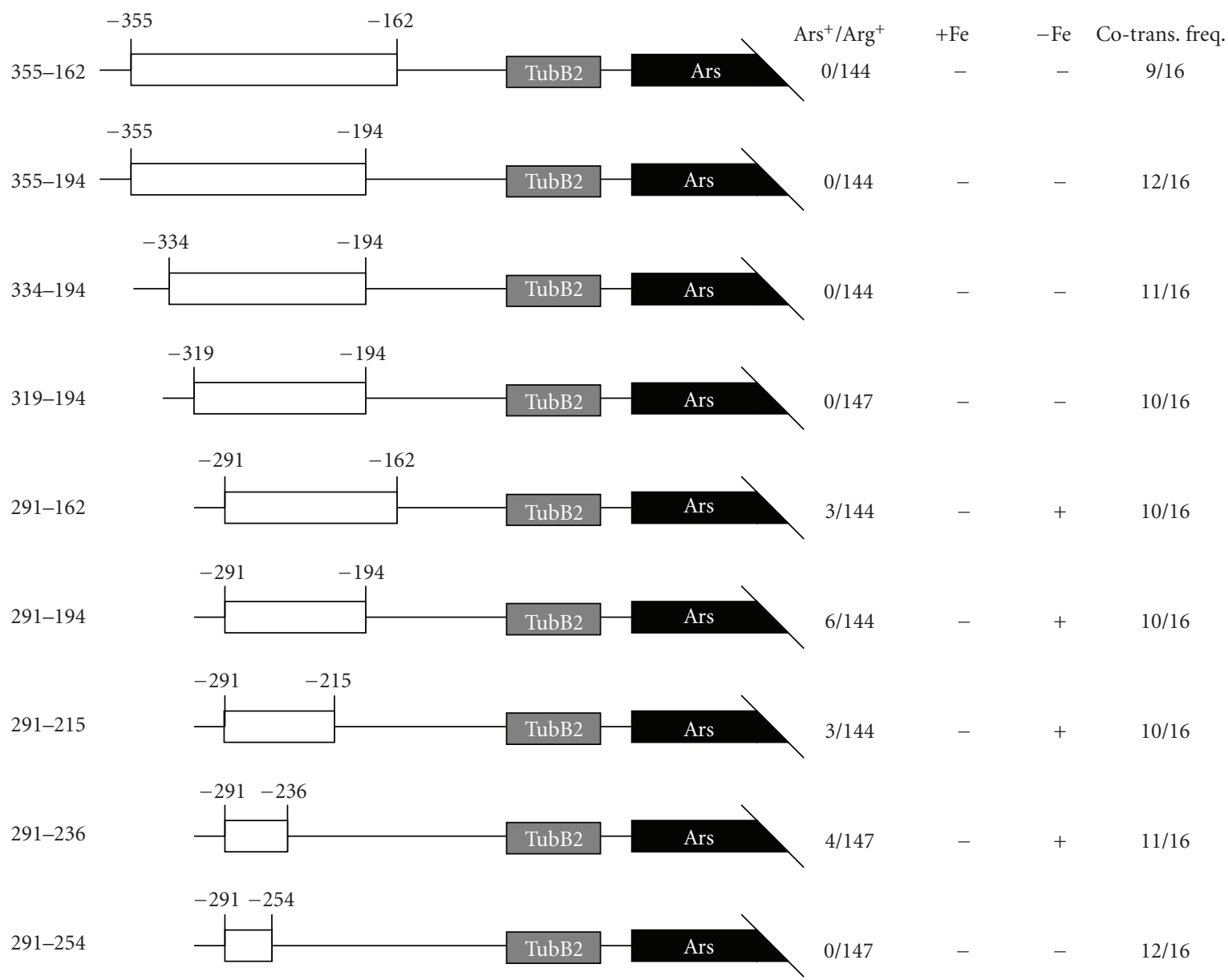

FIGURE 2: $5^{\prime}$ and $3^{\prime}$ deletion analysis of the FTR1 $-355 /-162$ promoter region. A series of $5^{\prime}$ and $3^{\prime}$ deletions from nucleotide -355 to -162 of the FTR1 promoter region were amplified by PCR and fused to the Ars reporter gene in pJD100 and cotransformed into the arginine requiring $C$. reinhardtii strain CC425 with pArg7.8. Arginine independent colonies were transferred to $+/-$ Fe TAP plates and sprayed with $10 \mathrm{mM} \mathrm{XSO}_{4}$ to visualize arylsulfatase activity. The fraction of arylsulfatase expressing colonies among the arginine independent colonies is indicated as $\mathrm{Ars}^{+} / \mathrm{Arg}^{+}$, and $+\mathrm{Fe}$ and $-\mathrm{Fe}$ indicate growth on $+/-\mathrm{Fe}$ TAP plates, and (+) and (-) indicate expression of the arylsulfatase gene. TubB2 stands for a minimal promoter element from the Chlamydomonas ß2-tubulin gene [42]. The cotransformation frequency was tested by PCR from 16 random selected Arg independent transformants.

3.2. The FeREs of FTR1 Localize in the $-291 /-236$ Region and a Negative FeRE Localizes in the -319/-292 Region. To verify that the $-291 /-254$ region is sufficient for iron responsive gene expression, a series of $3^{\prime}$ deletion constructs were generated as described in Figure 2 (355-162, 355-194, 334194, 319-194, 291-162, 291-194, 291-215, 291-236, and 291-254). These constructs were fused to the arylsulfatase reporter gene harbored by pJD100, which is driven by a basal promoter element derived from the Chlamydomonas B2-tubulin gene [42]. Verified constructs were delivered into C. reinhardtii CC425 by cotransformation with pArg7.8 and the response of the resulting strains to different iron concentrations was analyzed. The results indicated that the $-291 /-254$ fragment was not sufficient to confer promoter activity under low Fe condition (Figure 2, 291-254, 0/147 of $\left.\mathrm{Ars}^{+} / \mathrm{Arg}^{+}\right)$. Instead, promoter activity requires a region that spans -291 to -236 (Figure 2, 291-236, 4/147). Furthermore, our analyses indicated that this region contains two FeREs, one in the $-291 /-254$ region and the other in $-253 /-236$ region.

Interestingly, comparing promoter activity of regions 291-194 and 319-194, 334-194 and 355-194 (Figure 2, 291194, 319-194, 334-194, and 355-194) revealed a potential negative FeRE in the $-319 /-292$ region. The existence of this element is also clear when promoter activity between regions 291-162 and 355-162 was compared (Figure 2, 291-162 and 355-162).

3.3. Scanning Mutagenesis Analysis of the $-291 /-236$ and the -319/-292 Regions of FTR1. After localizing the positive FeREs to the $-291 /-236$ region and the negative FeRE to the 


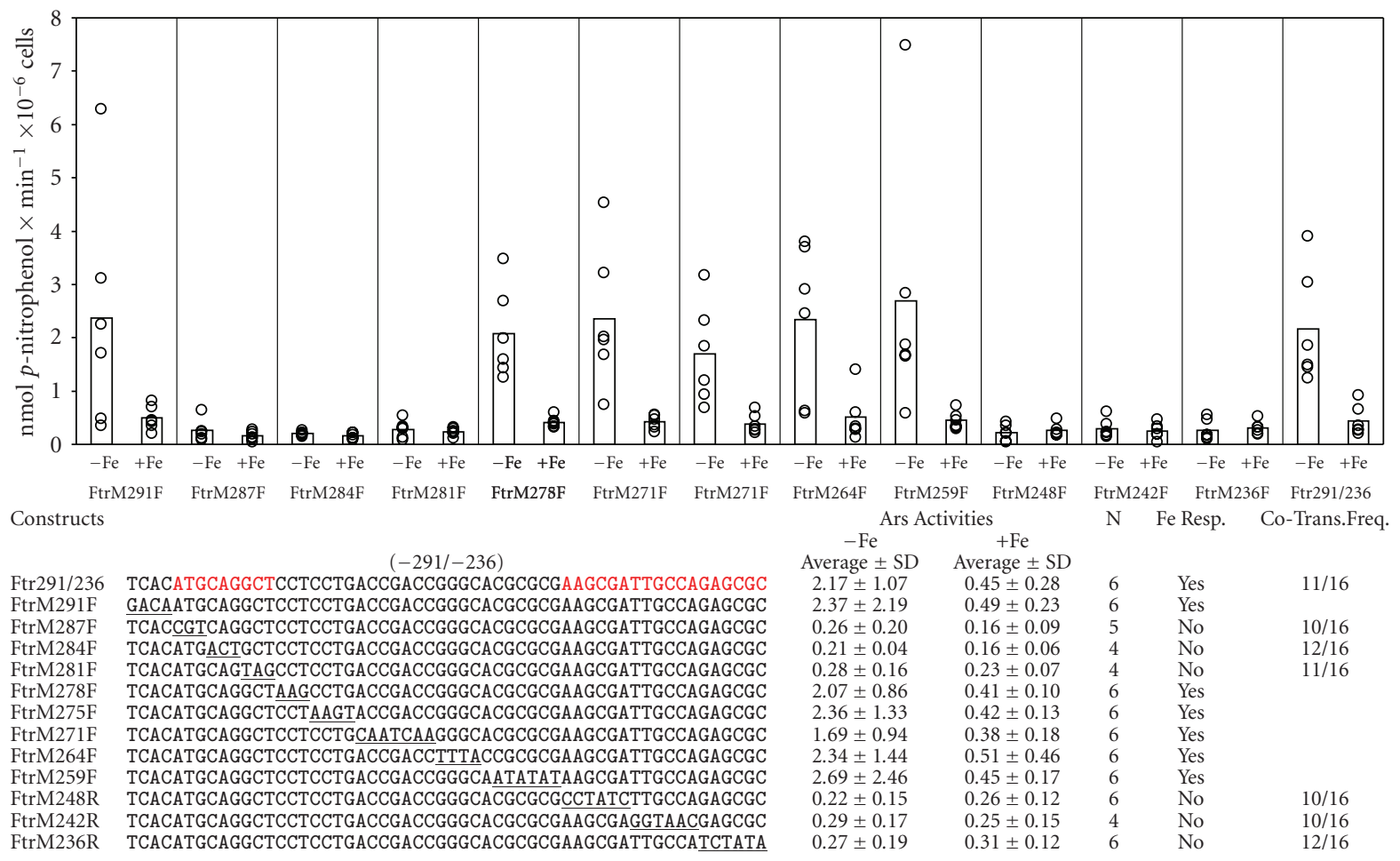

FIGURE 3: Scanning mutagenesis analysis of the FTR1 -291/-236 region. A series of nucleotide substitutions were introduced into the $-291 /-236$ region. The substituted nucleotides are underlined and red letters are the sequence of FtrFeRE1; and FtrFeRE2. The Ars activities (nmol $p$-nitrophenol $\times \min ^{-1} \times 10^{-6}$ cells) expressed by the mutated constructs were measured under $-\mathrm{Fe}(0 \mu \mathrm{M})$ or $+\mathrm{Fe}(18 \mu \mathrm{M})$ conditions. Black and white circles represent the Ars activities in independent transformants under $-\mathrm{Fe}$ or $+\mathrm{Fe}$ conditions, respectively. Bars indicated the median values. The number of the transformants tested for the activity is represented by N. The cotransformation frequency of the constructs was determined by PCR with 16 Arg independent transformants tested in each line.

$-319 /-292$ region, we performed a scanning mutagenesis to further identify the core sequence of the regulatory elements.

In the $-291 /-236$ region, constructs FtrM287F, FtrM284, FtrM281F, FtrM248R, FtrM242R and FtrM236R displayed relatively lower arylsulfatase (Ars) activity than the control 291-236 (construct with original nucleotide sequence from -291 to -236$)$ under low Fe $(0 \mu \mathrm{M})$ conditions (Figure 3, 0.26, 0.21, 0.28, 0.22, 0.29 and 0.27 compared with $2.17 \mathrm{nmol} p$-nitrophenol $\times \min ^{-1} \times 10^{-6}$ cells). These mutations did not lead to significant changes in Ars activity under low or high $\mathrm{Fe}(18 \mu \mathrm{M})$ conditions. On the other hand, in the constructs FtrM291F, FtrM278F, FtrM275F, FtrM271F, FtrM264F and FtrM259F, low Fe induced Ars activity to 4 to 6 times higher than high Fe condition and such activity was indistinguishable from the control (Figure 3, 2.37, 2.07, 2.36, 1.69, 2.34 and 2.69 compared with $2.17 \mathrm{nmol} p$-nitrophenol $\times \min ^{-1} \times$ $10^{-6}$ cells). These results suggest that the sequence from -287 to -279 of ATGCAGGCT and the sequence from -258 to -236 (AAGCGATTGCCAGAGCGC) were core sequences of FeREs that allowed the promoter to respond to Fe-deficient induction. We designated these elements as FtrFeRE1(ATGCAGGCT) and FtrFeRE2 (AAGCGATTGCCAGAGCGC), respectively.

In the $-319 /-292$ region constructs FtrM319F and FtrM313F, we observed lower promoter activities under
Fe-deficient conditions as control 319-194 (Figure 4, 0.28, 0.28 , and $0.26 \mathrm{nmol} p$-nitrophenol $\times \min ^{-1} \times 10^{-6}$ cells). Neither construct responded to low Fe levels, but both exhibited similar activities in media containing low or high Fe levels (Figure 4). However, constructs FtrM306F and FtrM299F remained highly responsive to low Fe conditions in a way similar to construct 291-194(Figure 4). These results suggest that sequence from -306 to -292 of AGTAACTGTTAAGCC is critical for Fe-deficiency negative regulation, and this element was designated as FtrFeRE3.

3.4. Fe-Regulated FTR1 Gene Expression Occurred at Transcriptional Level. To confirm that Fe-mediated gene regulation occurs at transcriptional level, we used real-time PCR to measure the mRNA levels under these conditions (Table 1). We selected several transformants containing the appropriate constructs for analyzing mRNA levels as well as Ars activity. Our results indicated that a significant amount of Ars mRNA was accumulated in transformants containing Ftr1179F, Ftr291F, 291-194, or FtrM291F, but not in those containing Ftr253, 319-194, or FtrM287F. These results are in good agreement with the data obtained by Ars activity assay, indicating that the Ars activity is a true measurement of the transcriptional level in response to iron deficient induction 
and that the observed iron regulation of gene expression occurs at the transcriptional level.

\section{Discussion}

In this study, we analyzed the Fe-deficiency-inducible gene FTR1 using deletion and scanning mutagenesis methods. FTR1 originally was identified as an Fe transporter that forms a complex with FOX1 for transferring Ferric iron across the plasma membrane into the cytosol. The FTR1 gene was believed to be involved in Fe-deficiency response in Chlamydomonas $[34,36]$. For example, under low $\mathrm{Fe}$ condition, its mRNA accumulates remarkably higher. Our results indicate that the $-291 /-236$ region is necessary and sufficient for Fe-deficiency-induced gene expression, and that the $-319 /-292$ region contains a negative FeRE (Figures 1 and 2). Further studies of the $-291 /-236$ region by scanning mutagenesis analysis revealed that one of the FeRE localized to $-287 /-279$ with the sequence of ATGCAGGCT, which we designated as FtrFeRE1. The other FeRE localized in $-253 /-236$ with the sequence AAGCGATTGCCAGAGCGC, which we designated as FtrFeRE2 (Figure 3). Similarly, analysis of the $-319 /-292$ region identified a novel negative FeRE (FtrFeRE3) in -306/-292 with the sequence AGTAACTGTTAAGCC (Figure 4).

Sequence analysis of FtrFeRE1 and FtrFeRE2 shows that the FtrFeRE1 contains a TGGCA-type-like FeRE with the sequence of TG-CA and the reverse complement sequence of FtrFeRE2 contains the sequence TGGCA, suggesting that the positive FeRE in FTR1 belongs to TGGCA-type-like FeRE (Figure 5).

In the previous studies, two of the Fox1-like type FeREs have been found in the $-789 /-283$ (CACATG) and the $-261 /-255$ (CACGCG) regions by investigating the promoter of FTR1 gene [38]. However, deletion of these regions from the promoter by overlapping extension PCR did not affect the iron-deficiency-inducible expression, suggesting that the sequence of CACATG was not sufficient to FTR1 gene. Interestingly, CACACG, the consensus sequence of the FOX1 FeRE1 differs to CACATG by only one nucleotide, implying that the nucleotide $\mathrm{C}$ is critical to the activities of the Fox1-type-like FeREs. In addition, the results in this study revealed that the TGGCA-type-like FeRE is a cis-acting element in iron-deficiency induction of the FTR1 gene.

In S. cerevisiae, iron homeostasis is maintained primarily through transcriptional control of gene expression. In response to variations of iron availability, the transcriptional regulator Aft1p/Aft2p directs the expression of a series of genes to control iron transport and subcellular compartmentalization. Promoters of these genes contain the consensus element CACCC recognized by the regulatory protein [17]. In contrast, little information is available about the positive transcriptional gene regulation in Chlamydomonas [47, 48]. Similarly, only one report about a negative control region, the 358 bp silencer region in $\mathrm{CAH1}$ gene is in response to low $\mathrm{CO} 2$ induction has, been published [49]. In Cyanobacterium, Synechococcus sp. PCC 7942, a negative regulatory element has been shown in the promoter region of $c m p A$, which encodes a 42-kD low-CO2-inducible protein [50]. Although Chlamydomonas and S. cerevisiae share a similar iron assimilation pathway when $\mathrm{Fe}$ is scarce, Chlamydomonas genome does not harbor homologs of Aft1p/Aft2p. These observations suggest that despite these two organisms use of a similar enzyme to regulate the affinity iron uptake under iron deficient conditions, their regulation mechanisms of low Fe response may be different. In our previous studies, we reported two types of FeREs, one in FOX1 gene with the core sequence $\mathrm{C}(\mathrm{A} / \mathrm{G}) \mathrm{C}(\mathrm{A} / \mathrm{G}) \mathrm{C}(\mathrm{G} / \mathrm{T})$ in two of the promoter regions [38], the other in FEA1 and ATX1 with the core sequence TGGCA in two of the regions $[39,40]$. These results suggest the existence of at least two potentially independent regulation mechanisms in response to $\mathrm{Fe}-$ deficiency in Chlamydomonas. The identification of a novel negative FeRE in this paper reveals the complex regulation mechanisms of Fe-deficiency-mediated gene expression in Chlamydomonas.

\section{Acknowledgments}

This work was supported by grants from the National Natural Science Foundation of China (30860028), from the National Nonprofit Institute Research Grants (CATASITBBZX0841), and from the National Natural Science Foundation of Hainan province (061012).

\section{References}

[1] E. Beutler, A. V. Hoffbrand, and J. D. Cook, "Iron deficiency and overload," Hematology, vol. 1, pp. 40-61, 2003.

[2] C. C. Philpott and O. Protchenko, "Response to iron deprivation in Saccharomyces cerevisiae," Eukaryotic Cell, vol. 7, no. 1, pp. 20-27, 2008.

[3] L. J. Martins, L. T. Jensen, J. R. Simons, G. L. Keller, and D. R. Winge, "Metalloregulation of FRE1 and FRE2 homologs in Saccharomyces cerevisiae," Journal of Biological Chemistry, vol. 273, no. 37, pp. 23716-23721, 1998.

[4] D. Radisky and J. Kaplan, "Regulation of transition metal transport across the yeast plasma membrane," Journal of Biological Chemistry, vol. 274, no. 8, pp. 4481-4484, 1999.

[5] C. Askwith, D. Eide, A. Van Ho, et al., "The FET3 gene of $S$. cerevisiae encodes a multicopper oxidase required for ferrous iron uptake," Cell, vol. 76, no. 2, pp. 403-410, 1994.

[6] R. Stearman, D. S. Yuan, Y. Yamaguchi-Iwai, R. D. Klausner, and A. Dancis, "A permease-oxidase complex involved in highaffinity iron uptake in yeast," Science, vol. 271, no. 5255, pp. 1552-1557, 1996.

[7] D. R. Dix, J. T. Bridgham, M. A. Broderius, C. A. Byersdorfer, and D. J. Eide, "The FET4 gene encodes the low affinity $\mathrm{Fe}(\mathrm{II})$ transport protein of Saccharomyces cerevisiae," Journal of Biological Chemistry, vol. 269, no. 42, pp. 26092-26099, 1994.

[8] D. Dix, J. Bridgham, M. Broderius, and D. Eide, "Characterization of the FET4 protein of yeast: evidence for a direct role in the transport of iron," Journal of Biological Chemistry, vol. 272, no. 18, pp. 11770-11777, 1997.

[9] R. Hassett, D. R. Dix, D. J. Eide, and D. J. Kosman, “The Fe(II) permease Fet4p functions as a low affinity copper transporter and supports normal copper trafficking in Saccharomyces cerevisiae," Biochemical Journal, vol. 351, no. 2, pp. 477-484, 


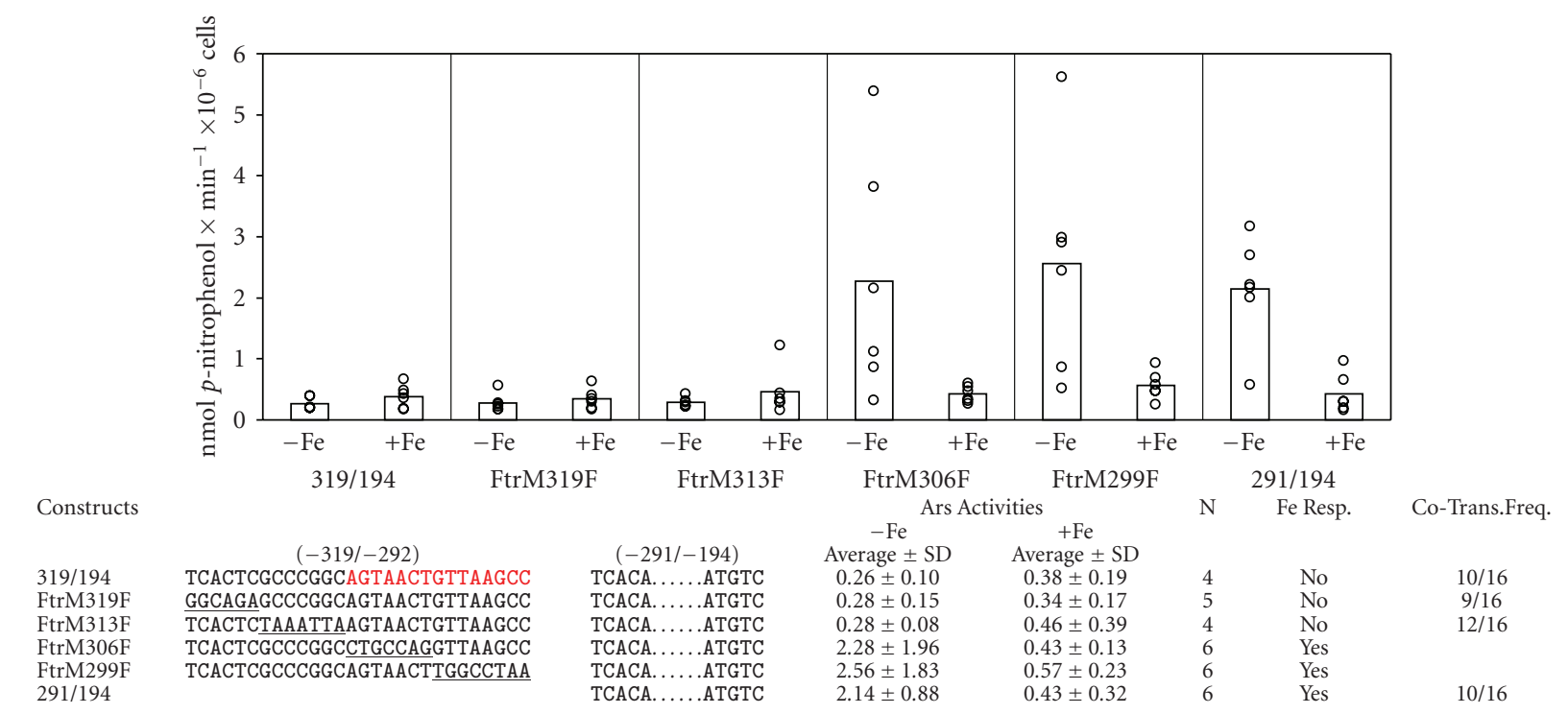

FIGURE 4: Scanning mutagenesis analysis of the FTR1 -319/-292 region. A series of nucleotide substitutions were introduced into the $-319 /-292$ region. The changed nucleotides are underlined. The conservation sequence of FtrFeRE3 is highlighted in red. The Ars activities (nmol $p$-nitrophenol $\times \min ^{-1} \times 10^{-6}$ cells) expressed from constructs were measured under $-\mathrm{Fe}(0 \mu \mathrm{M})$ or $+\mathrm{Fe}(18 \mu \mathrm{M})$ conditions. Black and white circles represent the Ars activities in independent transformants under $-\mathrm{Fe}$ or $+\mathrm{Fe}$ conditions, respectively. Bars indicate the median values. $\mathrm{N}$ represents the number of the transformants examined for the activity. The cotransformation frequency of the constructs was detected by PCR with 16 Arg independent transformants tested in each line.

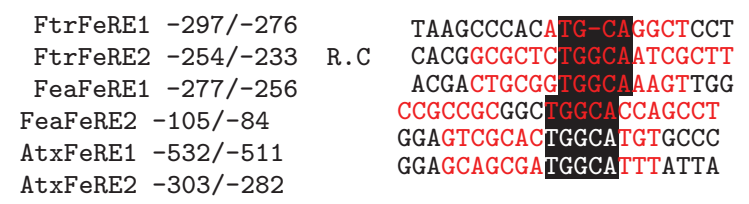

Figure 5: Sequence comparison of FtrFeRE1 and FtrFeRE2, FeaFeRE1 and FeaFeRE2, AtxFeRE1 and AtxFeRE2. White letters on black background indicate the conserved sequences TGGCA. The distances from the transcriptional starting sites or translation starting sites are shown in front of the sequence (the distance from the translational starting sites are marked with *).

2000.

[10] B. M. Waters and D. J. Eide, "Combinatorial control of yeast FET4 gene expression by iron, zinc, and oxygen," Journal of Biological Chemistry, vol. 277, no. 37, pp. 33749-33757, 2002.

[11] Y. Yamaguchi-Iwai, A. Dancis, and R. D. Klausner, "AFT1: a mediator of iron regulated transcriptional control in Saccharomyces cerevisiae," EMBO Journal, vol. 14, no. 6, pp. 12311239, 1995.

[12] P. L. Blaiseau, E. Lesuisse, and J. M. Camadro, "Aft2p, a novel iron-regulated transcription activator that modulates, with Aft $1 \mathrm{p}$, intracellular iron use and resistance to oxidative stress in yeast," Journal of Biological Chemistry, vol. 276, no. 36, pp. 34221-34226, 2001.

[13] J. C. Rutherford, S. Jaron, E. Ray, P. O. Brown, and D. R. Winge, "A second iron-regulatory system in yeast independent of Aft1p," Proceedings of the National Academy of Sciences of the United States of America, vol. 98, no. 25, pp. 14322-14327, 2001.

[14] J. C. Rutherford and A. J. Bird, "Metal-responsive transcription factors that regulate iron, zinc, and copper homeostasis in eukaryotic cells," Eukaryotic Cell, vol. 3, no. 1, pp. 1-13, 2004.

[15] Y. Yamaguchi-Iwai, R. Stearman, A. Dancis, and R. D. Klausner, "Iron-regulated DNA binding by the AFT1 protein controls the iron regulon in yeast," EMBO Journal, vol. 15, no. 13, pp. 3377-3384, 1996.

[16] Y. Yamaguchi-Iwai, R. Ueta, A. Fukunaka, and R. Sasaki, "Subcellular localization of Aft1 transcription factor responds to iron status in Saccharomyces cerevisiae," Journal of Biological Chemistry, vol. 277, no. 21, pp. 18914-18918, 2002.

[17] J. C. Rutherford, S. Jaron, and D. R. Winge, "Aft1p and Aft2p mediate iron-responsive gene expression in yeast through related promoter elements," Journal of Biological Chemistry, vol. 278, no. 30, pp. 27636-27643, 2003.

[18] M. Shakoury-Elizeh, J. Tiedeman, J. Rashford, et al., "Transcriptional remodeling in response to iron deprivation in Saccharomyces cerevisiae," Molecular Biology of the Cell, vol. 15, no. 3, pp. 1233-1243, 2004.

[19] J. M. De Freitas, J. H. Kim, H. Poynton, et al., "Exploratory and confirmatory gene expression profiling of mac $1 \delta$," Journal of Biological Chemistry, vol. 279, no. 6, pp. 4450-4458, 2004.

[20] N. J. Robinson, C. M. Procter, E. L. Connolly, and M. L. Guerinot, "A ferric-chelate reductase for iron uptake from soils," Nature, vol. 397, no. 6721, pp. 694-697, 1999.

[21] D. Eide, M. Broderius, J. Fett, and M. L. Guerinot, "A novel iron-regulated metal transporter from plants identified by functional expression in yeast," Proceedings of the National Academy of Sciences of the United States of America, vol. 93, no. 11, pp. 5624-5628, 1996.

[22] Y. O. Korshunova, D. Eide, W. G. Clark, M. L. Guerinot, and H. B. Pakrasi, "The IRT1 protein from Arabidopsis thaliana is a metal transporter with a broad substrate range," Plant Molecular Biology, vol. 40, no. 1, pp. 37-44, 1999.

[23] G. Vert, J. F. Briat, and C. Curie, "Arabidopsis IRT2 gene encodes a root-periphery iron transporter," Plant Journal, vol. 
26, no. 2, pp. 181-189, 2001.

[24] J. M. Petit, O. van Wuytswinkel, J. F. Briat, and S. Lobréaux, "Characterization of an iron-dependent regulatory sequence involved in the transcriptional control of AtFerl and ZmFerl plant ferritin genes by iron," Journal of Biological Chemistry, vol. 276, no. 8, pp. 5584-5590, 2001.

[25] J. Wei and E. C. Theil, "Identification and characterization of the iron regulatory element in the ferritin gene of a plant (soybean)," Journal of Biological Chemistry, vol. 275, no. 23, pp. 17488-17493, 2000.

[26] N. Okumura, N. K. Nishizawa, Y. Umehara, and S. Mori, "An iron deficiency-specific cDNA from barley roots having two homologous cysteine-rich MT domains," Plant Molecular Biology, vol. 17, no. 3, pp. 531-533, 1991.

[27] N. Okumura, N. K. Nishizawa, Y. Umehara, et al., "A dioxygenase gene (Ids2) expressed under iron deficiency conditions in the roots of Hordeum vulgare," Plant Molecular Biology, vol. 25, no. 4, pp. 705-719, 1994.

[28] T. Kobayashi, Y. Nakayama, R. N. Itai, et al., "Identification of novel cis-acting elements, IDE1 and IDE2, of the barley IDS2 gene promoter conferring iron-deficiency-inducible, rootspecific expression in heterogeneous tobacco plants," Plant Journal, vol. 36, no. 6, pp. 780-793, 2003.

[29] H. Q. Ling, P. Bauer, Z. Bereczky, B. Keller, and M. Ganal, "The tomato fer gene encoding a bHLH protein controls iron-uptake responses in roots," Proceedings of the National Academy of Sciences of the United States of America, vol. 99, no. 21, pp. 13938-13943, 2002.

[30] E. P. Colangelo and M. L. Guerinot, "The essential basic helixloophelix protein FIT1 is required for the iron deficiency response," Plant Cell, vol. 16, pp. 3400-3412, 2004.

[31] T. Brumbarova and P. Bauer, "Iron-mediated control of the basic helix-loop-helix protein FER, a regulator of iron uptake in tomato," Plant Physiology, vol. 137, no. 3, pp. 1018-1026, 2005.

[32] H. Y. Wang, M. Klatte, M. Jakoby, H. Baumlein, B. Weisshaar, and P. Bauer, "Iron deficiency-mediated stress regulation of four subgroup IbBHLH genes in Arabidopsis thaliana," Planta, vol. 226, pp. 897-908, 2007.

[33] Y. Yuan, H. Wu, N. Wang, et al., "FIT interacts with AtbHLH38 and AtbHLH39 in regulating iron uptake gene expression for iron homeostasis in Arabidopsis," Cell Research, vol. 18, no. 3, pp. 385-397, 2008.

[34] S. La Fontaine, J. M. Quinn, S. S. Nakamoto, et al., "Copperdependent iron assimilation pathway in the model photosynthetic eukaryote Chlamydomonas reinhardtii," Eukaryotic Cell, vol. 1, no. 5, pp. 736-757, 2002.

[35] S. J. Lin, R. A. Pufahl, A. Dancis, T. V. O'Halloran, and V. C. Culotta, "A role for the Saccharomyces cerevisiae ATX1 gene in copper trafficking and iron transport," Journal of Biological Chemistry, vol. 272, no. 14, pp. 9215-9220, 1997.

[36] A. Herbik, C. Bolling, and T. J. Buckhout, "The involvement of a multicopper oxidase in iron uptake by the green algae Chlamydomonas reinhardtii," Plant Physiology, vol. 130, no. 4, pp. 2039-2048, 2002.

[37] P. Rubinelli, S. Siripornadulsil, F. Gao-Rubinelli, and R. T. Sayre, "Cadmium- and iron-stress-inducible gene expression in the green alga Chlamydomonas reinhardtii: evidence for $\mathrm{H} 43$ protein function in iron assimilation," Planta, vol. 215, no. 1, pp. 1-13, 2002.

[38] X. D. Deng and M. Eriksson, "Two iron-responsive promoter elements control expression of FOX1 in Chlamydomonas reinhardtii," Eukaryotic Cell, vol. 6, pp. 2163-2167, 2007.
[39] X. Fei and X. Deng, "A novel Fe deficiency-responsive element (FeRE) regulates the expression of atxl in Chlamydomonas reinharditii," Plant and Cell Physiology, vol. 48, no. 10, pp. 1496-1503, 2007.

[40] X. W. Fei, M. Eriksson, J. H. Yang, and X. D. Deng, "A Fe deficiency responsive element (FeREs) with a core sequence of TGGCA regulates the expression of FEA1 in Chlamydomonas reinharditii," Journal of Biochemistry, vol. 146, pp. 157-166, 2009.

[41] E. H. Harris, The Chlamydomonas Source Book: A Comprehensive Guide to Biology and Laboratory Use, Academic Press, San Diego, Calif, USA, 1989.

[42] J. P. Davies, D. P. Weeks, and A. R. Grossman, "Expression of the arylsulfatase gene from the $\beta 2$-tubulin promoter in Chlamydomonas reinhardtii," Nucleic Acids Research, vol. 20, no. 12, pp. 2959-2965, 1992.

[43] K. L. Kindle, "High frequency nuclear transformation of Chlamydomonas reinhardtii," Proceedings of the National Academy of Sciences of the United States of America, vol. 87, pp. 1228-1232, 1990.

[44] R. Debuchy, S. Purton, and J. D. Rochaix, "The argininosuccinate lyase gene of Chlamydomonas reinhardtii: an important tool for nuclear transformation and for correlating the genetic and molecular maps of the ARG7 locus," EMBO Journal, vol. 8, no. 10, pp. 2803-2809, 1989.

[45] E. L. De Hostos, R. K. Togasaki, and A. Grossman, "Purification and biosynthesis of a derepressible periplasmic arylsulfatase from Chlamydomonas reinhardtii," Journal of Cell Biology, vol. 106, no. 1, pp. 29-37, 1988.

[46] K. J. Livak and T. D. Schmittgen, "Analysis of relative gene expression data using real-time quantitative PCR and the 2(Delta Delta C(T)) Method," Methods, vol. 25, pp. 402-408, 2001.

[47] K. Kucho, S. Yoshioka, F. Taniguchi, K. Ohyama, and H. Fukuzawa, "Cis-acting elements and DNA-binding proteins involved in $\mathrm{CO}_{2}$-responsive transcriptional activation of Cah1 encoding a periplasmic carbonic anhydrase in Chlamydomonas reinhardtii," Plant Physiology, vol. 133, no. 2, pp. 783793, 2003.

[48] J. M. Quinn, P. Barraco, M. Eriksson, and S. Merchant, "Coordinate copper- and oxygen-responsive Cyc6 and Cpx1 expression in Chlamydomonas is mediated by the same element," Journal of Biological Chemistry, vol. 275, no. 9, pp. 6080-6089, 2000.

[49] K. Kucho, K. Ohyama, and H. Fukuzawa, " $\mathrm{CO}_{2}$-responsive transcriptional regulation of $\mathrm{CAH} 1$ encoding carbonic anhydrase is mediated by enhancer and silencer regions in Chlamydomonas reinhardtii," Plant Physiology, vol. 121, no. 4, pp. 1329-1337, 1999.

[50] M. Ronen Tarazi, R. Schwarz, A. Bouevitch, J. LiemanHurwitz, J. Erez, and A. Kaplan, "Response of photosynthetic microorganisms to changing ambient concentration of $\mathrm{CO}_{2}$," in Molecular Ecology of Aquatic Microbes, I. Joint, Ed., vol. G38 of NATO ASI Series, pp. 323-334, Springer, Berlin, Germany, 1995. 

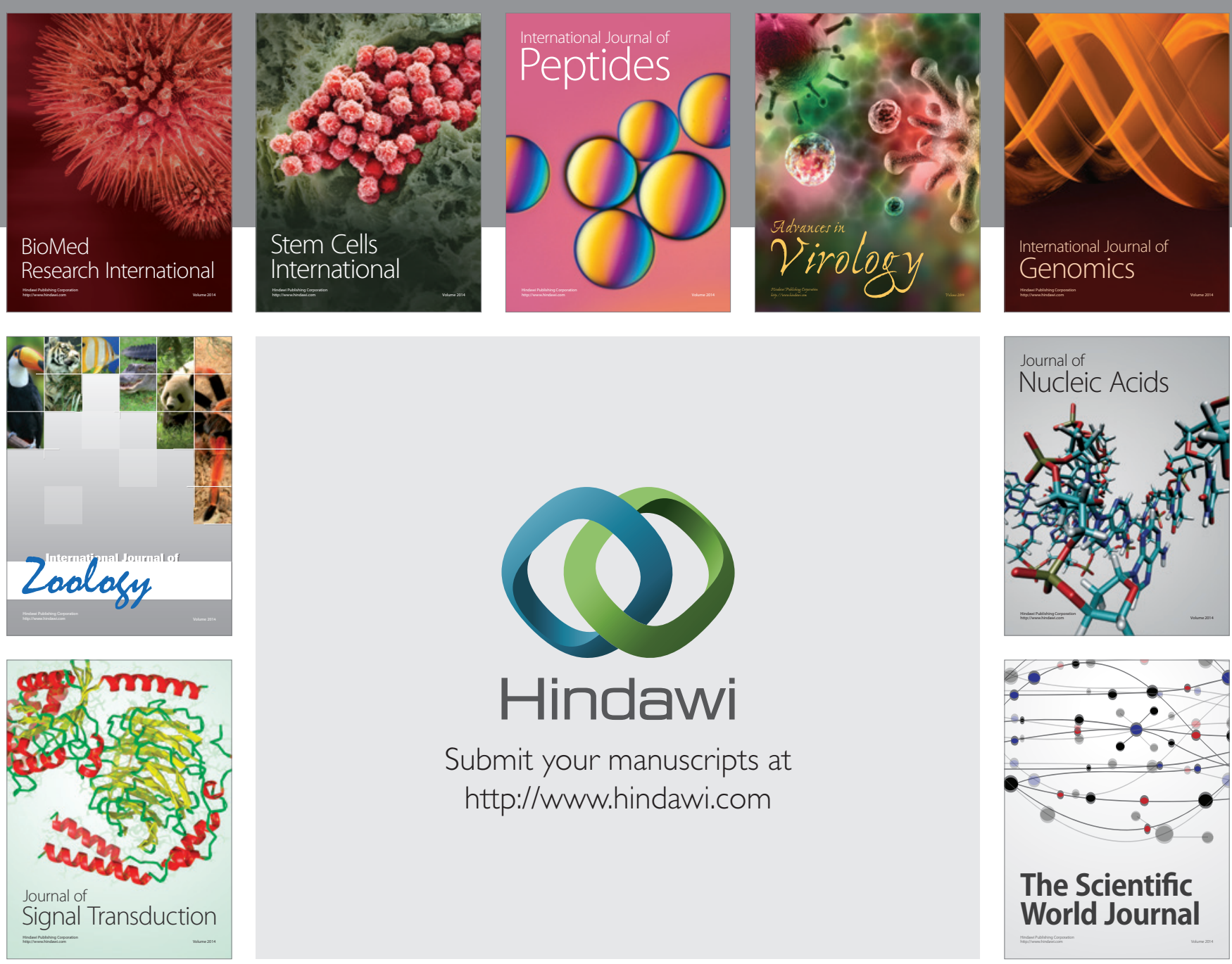

Submit your manuscripts at

http://www.hindawi.com
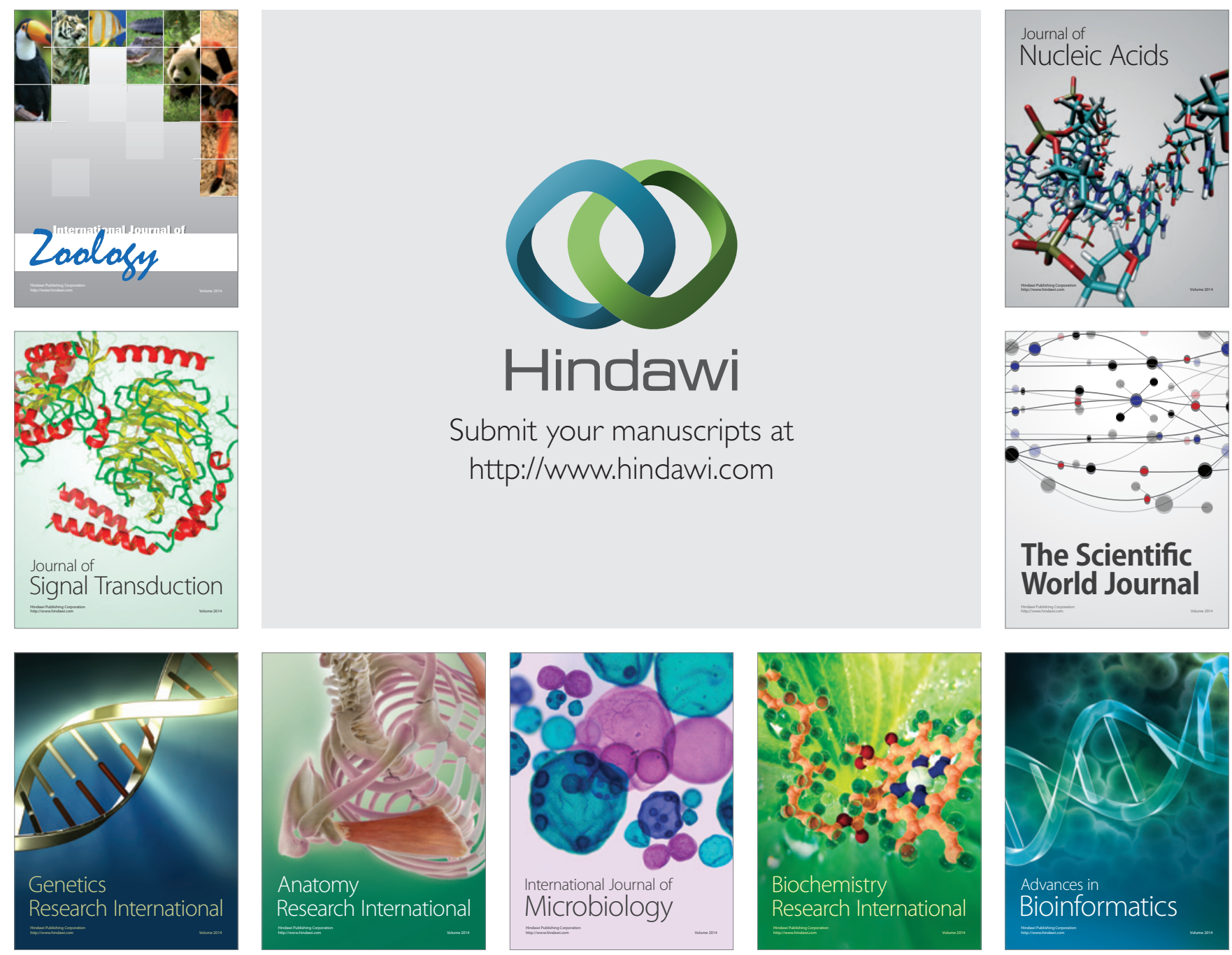

The Scientific World Journal
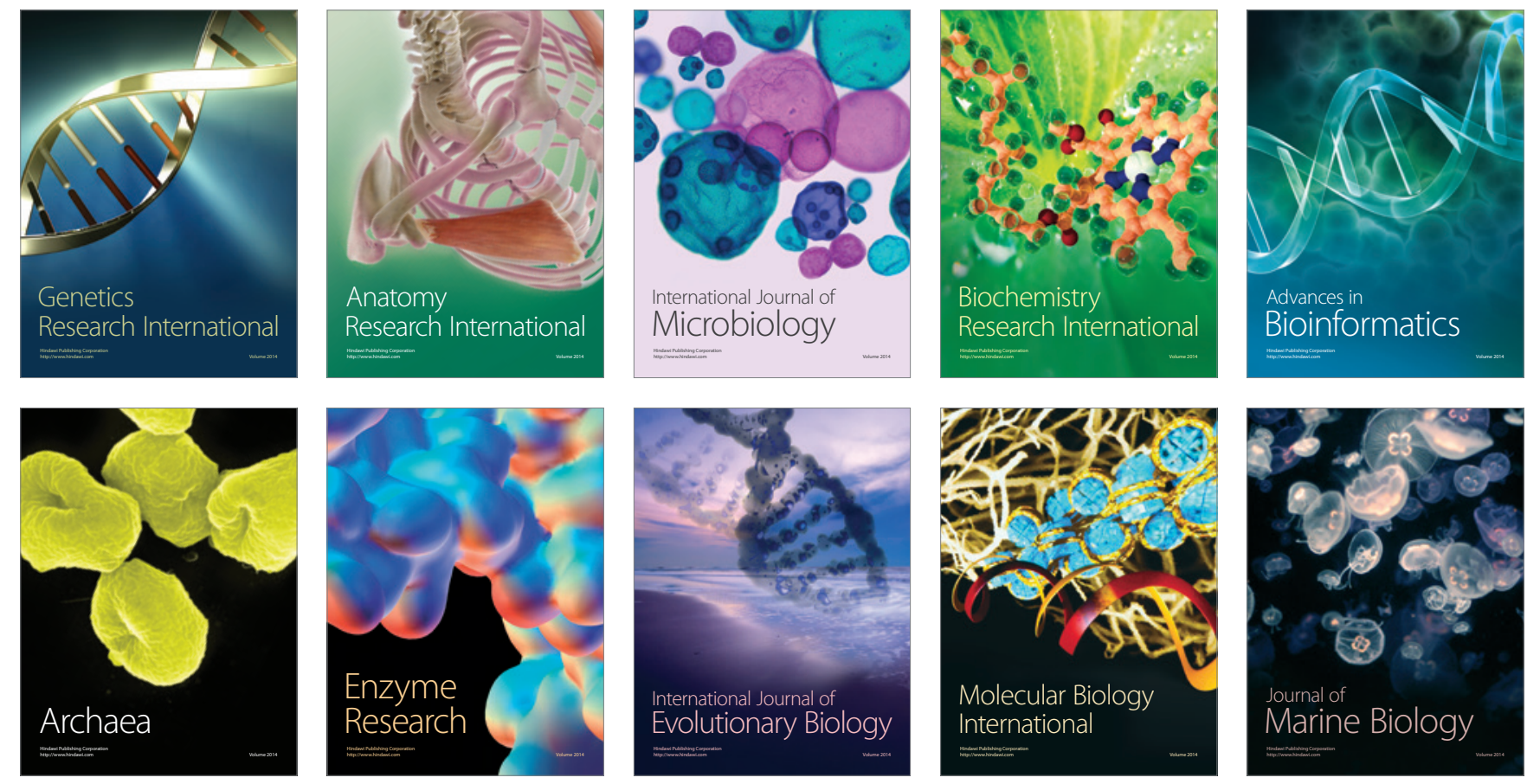